ISSN 0819-2642

ISBN 0734025726

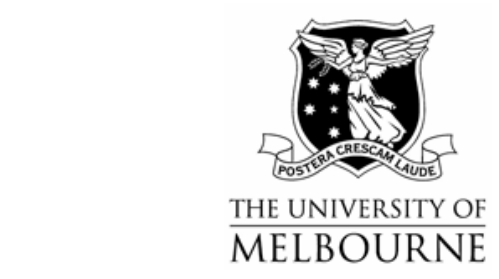

THE UNIVERSITY OF MELBOURNE

DEPARTMENT OF ECONOMICS

RESEARCH PAPER NUMBER 916

SEPTEMBER 2004

\title{
TO TEACH OR NOT TO TEACH? PANEL DATA EVIDENCE ON THE QUITTING DECISION
}

by

Paul Frijters

$\&$

Michael A. Shields

$\&$

Stephen Wheatley Price

Department of Economics

The University of Melbourne

Melbourne Victoria 3010

Australia. 
TO TEACH OR NOT TO TEACH?

\title{
PANEL DATA EVIDENCE ON THE QUITTING DECISION
}

\author{
Paul Frijters $^{1}$, Michael A. Shields ${ }^{2}$ and Stephen Wheatley Price ${ }^{3}$ \\ ${ }^{1}$ RSSS, Australian National University, Australia \\ ${ }^{2}$ Department of Economics, University of Melbourne, Australia \\ ${ }^{3}$ Department of Economics, University of Leicester, UK
}

\begin{abstract}
The question we address in this paper is which factors influence the quitting decision of public sector teachers in England and Wales, using a nationally representative panel data set over 19972003. We document the outcomes of former teachers, fit single and competing-risks duration models and examine the influence of relative pay on retention. Surprisingly, we find that teachers who move to outside employment earn 22\% less pay, work longer hours, in largely nonprofessional occupations and mainly stay within the public sector. We estimate that a $10 \%$ increase in teachers' relative pay would reduce annual quitting rates by less than $1 \%$.
\end{abstract}

JEL Classifications: J45, J63, I18

Keywords: $\quad$ Teachers, Panel Data, Wages, Quitting

Word count: 8500

Corresponding author: Michael A. Shields, Department of Economics, University of Melbourne, Parkville, Melbourne, Australia 6010: E-mail: mshields@unimelb.edu.au. The data are used with the permission of the Office for National Statistics, United Kingdom and the Data Archive at the University of Essex. The usual disclaimer applies. 
"What nobler employment, or more valuable to the state,

than that of the man who instructs the rising generation."

Marcus Tullius Cicero (106BC - 46BC)

\section{Introduction}

There is a global shortage of schoolteachers (Siniscalco, 2002). Demographic trends, particularly in low-income countries, and politically-driven reductions in pupil-teacher ratio targets, primarily in the industrialised world, have increased the demand for teaching professionals. However, in most European countries recruitment and retention problems have led to the supply of public sector teachers falling below desired levels (EURYDICE, 2002). ${ }^{1}$ In particular, relatively low starting salaries and poor earnings growth (Dolton, 1990; Manski, 1987; Zabalza et al., 1979) are believed to discourage many graduates from entering the profession. Additionally, the perceived decline in the status of the profession, increased government intervention and worsening working conditions appear to be increasing the likelihood of experienced teachers quitting for private sector jobs or leaving the labour force altogether (Smithers and Robinson, 2003).

In England \& Wales ${ }^{2}$ there is an ongoing shortage of qualified teachers in the public sector (of government maintained schools) which we estimate to be around 23,400 in 2003. This is equivalent to around $6 \%$ of the total number of qualified teachers that would be consistent with maintaining government pupil-teacher ratio (PTR) targets (DFES, 2004). ${ }^{3}$ The majority of the shortfall (58\%) is in secondary schools (for 11-18 years olds) where the PTR has been gradually worsening over the past decade. In primary (for 5-10 year old children) schools the PTR has been fairly stable over this period. Official government figures only reported a vacancy rate of around $1 \%$ or 3,450 positions in January 2003 (DFES, 2004). However, the definitions are disputed due to the fact that many teaching posts are filled with temporary or unqualified staff (NUT, 2003). Irrespective of the absolute position, the proportion of teachers changing job (turnover) or leaving public sector teaching altogether (wastage) is quite high. Smithers and Robinson (2003) report a turnover rate of $14.1 \%$ and a wastage rate of $7.9 \%$ amongst their sample of full-time teachers in England during 2002. Government figures show that a total of 27,870 teachers left full-time public sector positions, between March 2001 and March 2002, with the vast majority of these (21,230) quitting the profession and the remainder (6,640) retiring (DFES, 2004).

\footnotetext{
${ }^{1}$ Cited in Smithers and Robinson (2003).

2 Throughout the paper we focus on the teaching labour market in England and Wales as educational funding and policy is separately determined in Scotland and Northern Ireland.

${ }^{3}$ This estimate is derived from DFES figures on numbers of full-time equivalent qualified teachers and pupils, in primary and secondary schools in England and Wales, in January 2003 and PTR targets for primary schools of 21.2 and for secondary schools of 16.0. Actual PTRs were 22.2 and 17.1, respectively, at this time.
} 
In this paper we explore the factors which influence the decision by teachers in the UK to leave public sector employment over the period 1997-2003. In order to do this we have constructed a unique and large nationally representative dataset which contains panel data on teachers, both whilst they are employed in the public sector and in their subsequent labour market state. Importantly, we are able to observe individuals' employment or non-participation activity every three months, on upto five occasions, which provides us with detailed information on the short-term dynamics of teachers job changes. Our econometric investigation involves the implementation of duration models to explore the characteristics influencing the quitting decision of public sector teachers and, in particular, the importance of relative wage rates. Interestingly, given the paucity of information concerning the labour market outcomes of former teachers, we are also able to compare reported earnings, hours of work and other factors in both the public sector teaching position and in the subsequent job. The results of our analysis will therefore help to inform the current and future policy debates concerning teacher retention.

The paper is set out as follows. Section 2 outlines the main changes in the UK teaching workforce over the period of our study, whilst Section 3 provides an overview of the relevant international literature on teacher recruitment and retention. Section 4 introduces the data, describes the salient characteristics of the sample and documents the labour market outcomes of former public sector teachers. Our econometric methodology in outlined in Section 5 with a discussion of the estimation results being provided in Section 6. The contribution of the paper is summarised in Section 7 and some policy conclusions are drawn.

\section{The UK Teaching Workforce, 1997-2003}

According to official government statistics (DFES, 2004) ${ }^{4}$ the number of full-time equivalent qualified teachers in the public sector grew from 360,000 to 364,200 between 1997 and 2003. However, there is considerable evidence of a longer-term decline in teacher supply (see also Chung et al., 2004, Figure 1, p. 7) as shown by the equivalent figures for 1985 (398,300), $1990(375,900)$ and 1995 (360,900). One strategy used by the government to tackle teacher shortages has been a dramatic increase in the employment of support staff whose numbers increased by 65\%, from 136,500 to 225,400 , over the same period. In addition, the UK government has granted an increasingly large number of work permits to qualified teachers from non-EU countries and actively recruited overseas. In September 2000 the government also implemented a new wage structure for teachers, which gave managers some flexibility over pay, in order to attract recruits in shortage subjects, such as Mathematics and Science, and to more expensive geographical regions of the UK,

\footnotetext{
${ }^{4}$ Much of the statistical information referred to in this section is drawn from various tables in this publication.
} 
especially London and the South East. The potential of wage enhancements for experienced teachers, and those carrying higher administrative burdens, was also provided in order to try and retain such staff. From April 2001 “Golden Hello” one-off payments have also been available to new recruits in specialist subject areas.

Inflows into public sector teaching jobs in the UK are, to a large extent, dependent on returnee teachers and overseas recruitment, rather than newly qualified teachers. Between March 2001 and March 2002 over 26\% of full-time entrants, and 58\% of part-time hires, were individuals who had previously taught in the public sector. A further $20 \%$ of full-time recruits, and $36 \%$ of part-time entrants, had never previously held a teaching position in the UK. This means that only 54\% of fulltime, and 6\% of part-time, inflows into public sector teaching jobs in the UK were newly qualified teachers. Indeed the proportion of teachers who successfully completed their initial teacher training in 2001 and were employed in teaching jobs, in March 2002, was only 76\%. Furthermore, these 16,540 new recruits represent only $60 \%$ of the cohort initially accepted into teacher training programs in 2000. A final problem with regard to attempting to solve the teaching shortfall with increasing the number of initial teacher training places is that previous research indicates that around one-third of new hires quit public sector teaching within five years (Dolton and van der Klaauw, 1995a).

The importance of teacher retention is highlighted by noting that, on the $31^{\text {st }}$ March 2002, there were 80,800 qualified teachers, not currently employed as teachers by the government, who were under the normal retirement age ${ }^{5}$ and who had previously worked in a public sector teaching position between 1997 and 2002. Only 30,000 of these were females of child-bearing age, with a further 31,000 being females between the ages of 40 and 60 and 19,800 being males under 60. An additional reserve army of qualified teachers numbering 75,400, who had worked in a public sector job between 1987 and 1996, were currently employed elsewhere or outside the labour force. A final pool of 81,700 qualified teachers were present in the UK, but had never worked as a teacher in the public sector. These figures highlight the fact that there is no shortage of qualified teachers in the UK, with the total potential supply of qualified personnel being ten times the estimated current supply deficit. However, the policy challenge is to attract and, especially, retain the services of teachers in the public sector. This is all the more pressing as over $25 \%$ of currently employed teachers are within ten years (and over 55\% are within twenty years) of the normal retirement age.

A number of survey-based studies have examined the likelihood of teachers quitting the public sector in the UK. NUT (2004) cites a poll in which one third of teachers reported expecting to leave

\footnotetext{
${ }^{5}$ Excluding those who had officially retired early.
} 
the profession within the next five years. The most commonly cited reasons were excessive workload, especially bureaucratic paperwork, an overload of government-driven initiatives and a culture of management driven by performance-related targets. Smithers and Robinson (2003) found five main factors which were associated with teacher quits during 2002: workload issues, the desire for a new challenge, school-related circumstances (including problems with student discipline and behaviour particularly in secondary schools), personal circumstances and wages. Interestingly pay was the least important of these factors whilst workload was the main area of dissatisfaction. Sturman (2002) reports findings from a teacher survey that indicates teachers self-indicate greater levels of work-related stress than other employees. Interestingly, their reported job satisfaction levels are above average. These two factors had the most influence on reported commitment to the job, whereas dissatisfaction with salary level was relatively unimportant.

\section{Econometric studies of teacher recruitment and retention}

Despite the facts that teaching represents one of the largest occupations in most industrialised countries, that many countries report ongoing problems with teacher supply shortages and that pupil-teachers ratios are believed to be an important influence on the outcomes of the education process, the econometric literature concerning this professional labour market is quite limited. One prime cause of this reality is the dearth of detailed panel data on teachers. Empirical studies mainly explore the factors which influence the recruitment and retention of teachers, with some attention (particularly in the US) on how policy might influence the skill and ability composition of employed teachers. Here we will briefly survey the main findings from this research focusing on what is currently known about the factors which influence teacher retention, especially the importance of relative wages. More detailed reviews of the literature can be found in Chevalier et al. (2002), Dolton (2004) and Stinebrickner (2001a).

Many of the earliest econometric explorations of teacher supply focused on the influence of wage levels on recruitment to the profession amongst graduates. For the US Manski (1987) found that a $10 \%$ increase in weekly wages would increase the supply of teachers from a graduate cohort by 20\%. Flyer and Rosen (1997) argued that a graduate's choice of profession might be influenced by lifetime considerations. In particular, they hypothesised that, in teaching, labour force interruptions receive a lower wage penalty than in other career options. Hence individuals who anticipated spending less time in labour market activity would rationally choose such a low risk occupation. One aspect to this is, for those who anticipate absences for child-rearing, the added convenience of matching paid holiday with school age children's vacations therefore minimising childcare costs and maximising parent-child interactions. 
Zabalza et al. (1979), using UK time series data for 1963-1971, found significant impacts of relative starting wages, and subsequent wage growth, on the probability of recruiting teachers in the public sector in the UK, using time series data. When these aspects were disaggregated by gender they found that male teachers were much more responsive to changes in the wage growth than females. The graduate unemployment level was also shown to be inversely related to the probability of becoming a teacher, which is confirmed by Chung et al. (2004) using a much longer UK time series over the period 1960-2001. Similar general wage results were reported by Dolton (1990), based on UK graduate cohort data from 1980, who finds that the probability of becoming a teacher is greater the higher are relative starting salaries, the greater is teacher earnings growth and the lower is the rate of increase in non-teacher wages. In a UK paper modelling returnees to teaching, Dolton and van der Klaauw (1995b) find that a 10\% increase in relative teaching wages raises the probability of a recently qualified teacher returning to the public sector by 4 percentage points (from 59\% to 63\%).

Several US studies have explored the influence of wage changes on the quality of the teaching workforce. Ballou and Podgursky (1985) find only modest benefits on the ability composition of the US teaching pool from a simulated $20 \%$ pay rise. Even this policy change would still leave the cognitive ability of teachers below the graduate average, and the full effect would only be realised after decades as the retention of current teachers would also be enhanced. Through targeting pay rises to the more able teachers, as measured by SAT scores, Stinebrickner (2001b) argues that the average ability of the pool of employed teachers would be increased through the retention of the more able teachers. A contrasting influence on the average quality of teachers in the public sector is provided by Murnane (1994). He provides evidence of selective attrition, over the first four years of teaching, in a sample of teachers who quit primary schools in a large urban district in the US. Teachers whose students have lower test scores, and whose evaluations by their supervisors was least satisfactory, are most likely to leave employment in these more challenging schools. Hence, in these schools it is the least effective teachers who quit, enhancing the average productivity of the remaining workforce.

Most of the econometric studies have examined the influence of wages on retention rates. Two papers by Murnane and Olsen $(1989,1990)$ show that higher teaching salaries in Michigan and North Carolina tended to increase the duration in teaching, but were less important to those who enter the profession at more advanced ages. They also find that the higher is the opportunity cost of teaching in the US, as measured by area of specialty and average non-teaching graduate salaries by discipline, the shorter is the duration in teaching. Stinebrickner (1998) also found, using US longitudinal data on qualified teachers over the first eleven years of their career, that higher wages 
significantly increased retention rates, whilst Brewer (1996) argued that future career opportunities influenced the decision to remain in teaching. More specifically, Stinebrickner (2001a) showed that a $25 \%$ salary raise would increase the proportion of time spent in first teaching jobs by $50 \%$, using proportional hazard models. One aspect of teacher workload, namely of pupil-teacher ratios, was found to be insignificantly related to the quitting decision. The wage effect was particularly influential in reducing time in non-teaching employment rather than in non-participation for US teachers. Exits to the latter were more likely if the teacher was married or had recently had a child.

Evidence from the UK, by Dolton and van der Klaauw (1995a,b), found that a 10\% increase in relative teaching wages reduced the probability of newly qualified teachers leaving the public sector by $3 \%$ points (from $34 \%$ to $31 \%$ ), during their first continuous teaching spell. Using a competing risks framework, Dolton and van der Klaauw (1999) find a positive influence of higher wages in the non-teaching sector on the likelihood of UK teachers moving into such employment. More recent data, examined in Chevalier et al. (2002), shows that a 10\% increase in the relative starting salaries of teachers raises the probability of a graduate still being a teacher after 6 years by $10 \%$. Graduates living in London and the South East and those in Science or Social Science disciplines were also more likely than others to quit the profession. Furthermore, better qualified graduates, with an above average grade in their first degree or a higher degree, were less likely to enter the profession. Teacher retention also depended on the state of the labour market at the time of graduation, as confirmed by Chung et al. (2004), using provide time series evidence for the UK over the period 1960-2001.

In one of the few studies which utilises data on what teachers do after they leave, Scafidi et al. (2002) show that around 95\% of quitting teachers in the State of Georgia do not leave the profession for higher wage employment in other sectors. Many leave for part-time work or an administrative job in the education sector. They argue that increases in teacher salaries will therefore be ineffective in increasing retention rates. Stinebrickner (2002) argues that childcare provision may be an efficient way of inducing female teachers to remain in the profession whilst their children are young. The cost of the alternative policy, of wage enhancements, is estimated to be very large. This is particularly pertinent for the US as, in his sample, $60 \%$ of females who quit teaching left the labour force altogether. Some 38\% of these quitters return to teaching within 5 years, which is a larger proportion that the $28 \%$ of returnees, over the same timeframe, who had originally move to different occupations.

Importantly, as Loeb and Page (2000) argue, the influence of pay on retention is confounded by differences in school characteristics in most studies of teacher retention. An exception is Hanuschek et al. (2004). They provide evidence from public schools in Texas that school composition and 
characteristics, as measured by the proportion of academically disadvantaged and ethnic minority students, significantly influence the likelihood of teachers switching to other schools. ${ }^{6}$ Compensating differentials of between $25 \%$ and $40 \%$ would be required to induce the dominant group of white females to remain as teachers in the less desirable schools. Further evidence of the impact of non-pecuniary factors on teacher quitting decisions is provided by Falch and Strom (2004), based on matched employer-employee panel data from Norwegian primary and lower secondary schools. They show that quitting rates are higher amongst teachers working in schools with higher proportions of minority and special needs pupils and in regions with higher living costs. A doubling of the local unemployment rate is also found to reduce quitting rates by $0.8 \%$ points.

In many respects even the most recent literature on teachers significantly lags behind recent developments in both the theoretical and econometric approaches to modelling labour supply more generally (Blundell and MaCurdy, 1999). To a large extent these limitations are data determined. For instance the extensive panel data studies needed to understand the role of household bargaining in the empirical framework, control for unobservable individual heterogeneity or identify the wage effect through an exogenous change to wages, are unavailable in most countries, including the US. Furthermore, detailed information on school and student characteristics, teacher ability and productivity and on the nature and duration of the subsequent employment or non-participation states of former teachers are also scarce. Hence a definitive overview of the relative importance of different factors in the decision to become, or cease being, a teacher in the public sector has yet to be attained.

We now turn to an empirical examination of the quitting decision, amongst UK teachers, using data from a different perspective to previous work. In particular our data contains relatively rich short-term dynamics and more detailed information on non-teaching outcomes than previously available.

\section{Data and a descriptive portrait of teacher quits}

\subsection{Data}

Our sample is derived from the Quarterly Labour Force Survey (QLFS) of the United Kingdom. The Labour Force Survey has been undertaken since 1973. Its primary purpose is to collect internationally comparable employment and unemployment data at a regional and national level for the UK. The questionnaire covers areas such as economic activity, education and training, household structure, qualifications, job search behaviour and working environment. At the

\footnotetext{
${ }^{6}$ See Theobald (1990) and Theobald and Gritz (1996) for earlier US evidence of the effect of school characteristics on teacher retention.
} 
beginning of 1992 a quarterly panel element was introduced. The total number of households successfully questioned each quarter is approximately 64,000, amounting to some 167,000 persons. Each household is questioned for five successive surveys (termed waves 1 to 5), so that if the household is first surveyed in the Spring quarter (interviews conducted between March and May) of one year (wave 1) interviews will be attempted with that household for the successive Summer, Autumn and Winter quarters (waves 2, 3 \& 4, respectively) concluding with the Spring quarter of the following year (wave 5). Hence, each respondent may be observed in the sample up to 5 times and only approximately $20 \%$ of the sample (those in wave 1 ) are new to the survey each quarter.

The panel element of the QLFS has been relatively under-utilised in empirical work. It is a large nationally representative data source that provides a longitudinal sample of public sector teachers, with three monthly observations. This allows us to track more immediately, and perhaps with greater precision than annual panel or cohort data sets, those teachers who leave the public sector, or the profession altogether. Importantly, since 1997 the survey collects wage information at both wave 1 and wave 5, so we are able to observe wage changes for those teachers who left the public sector for outside employment. Due to the frequency of observations in the data, and the large sample size, we can perform more reliable econometric analysis using this panel dimension. To obtain our sample we constructed a series of 22 overlapping panel datasets, the first of which comprises those individuals who are first successfully interviewed in the Summer QLFS of $1997^{7}$ (interviews conducted between June and August), following them through to the Summer QLFS of 1998. The next panel was first sampled during the Autumn QLFS of 1997 (interviews conducted between September and November), and completed its duration in the panel in the Autumn QLFS of 1998, whilst the third panel of individuals entered during the Winter QLFS of 1997 (interviews conducted between December 1997 and February 1998), and exited after the Winter 1998 QLFS, and so on. Our twenty-second and final panel comprises individuals whose first interview took place during the Autumn QLFS of 2002 and whose final interview was undertaken in the Autumn QLFS of 2003. This provides a total sample of just under 2 million observations on 408,805 individuals (48.5\% male, 51.5\% female) of working age (16 to 64 ).

\subsection{Sample characteristics}

From the total number of observations we have drawn out all those individuals who reported to be a public sector teacher, at least once in any of the waves they were interviewed in and who resided in

\footnotetext{
${ }^{7}$ We choose this as the first quarter as information about wages, in both the first and final waves, is only available from Spring 1997 quarter QLFS and the classification of degree subjects is only consistently available from the Summer quarter of 1997.
} 
England \& Wales. ${ }^{8}$ This produced a sample of 29,801 observations on 7,989 different teachers. ${ }^{9}$ Attrition in the QLFS is a significant problem with only $51.2 \%$ of teachers observed in all five waves, and an average duration in the panel of 3.75 waves. Reflecting the female dominated nature of teaching only $33.8 \%$ of the sample are male, and the average age is 42.9 years. Just over $78 \%$ are married or cohabiting, $6.9 \%$ are immigrants to the UK and only $2.9 \%$ are from a ethnic minority group. Within the five quarter time frame, around $94.1 \%$ of the observations are currently in public sector teaching, $0.7 \%$ are in private sector teaching, $1.7 \%$ are in other public sector occupations, $0.3 \%$ in other private sector employment and $3.3 \%$ are not working. We refer to the latter group as non-participants, though it does include a small number of unemployed individuals. Our data also captures a number of individuals who entered into teaching during the five waves of the sample survey period. However, the substantial group of teachers who we observe leaving public sector over this time are the focus of this paper.

The public sector teaching workforce observed in our data comprises some $36.4 \%$ who are working in a job requiring managerial duties, with 6.9\% employed in a position with supervisory duties leaving $55.9 \%$ of teachers reporting no managerial or supervisory responsibilities. Just under $41 \%$ of our sample are employed as primary school teachers, with $45 \%$ working in secondary schools, 6.9\% teaching specialist needs children and 2.7\% employed as school inspectors. The vast majority of teachers (85.9\%) report their position as being permanent, work full-time (79.9\%) and have received training in the thirteen weeks prior to interview (60.2\%). Interestingly, just over 5.5\% of teachers report to be actively searching for a new job. However, only $10 \%$ of these indicate that dissatisfaction with pay is the main reason for job search activity, with around $20 \%$ being unhappy with their hours of work. Indeed the average number of weekly working hours reported by the public sector teachers in our sample is 34 .

As expected with a predominantly graduate profession, over $92 \%$ of public sector teachers in our sample hold a degree or higher degree. Teachers whose degree or higher is in a Science subject (biological, medical or physical science, mathematics, computing or engineering) comprise only $13.2 \%$ of our sample, with an even smaller proportion having completed a degree in a Social Science (including Economics or Business) subject. These figures reflect the widely reported

\footnotetext{
${ }^{8}$ Scotland and Northern Ireland have separately controlled educational provision.

${ }^{9}$ Our sample size of teachers is much greater that obtained from pooling the five Graduate Cohort surveys used by Chevalier et al. (2002), who have 3201 teacher observations. Our data also has the benefits of recording occupational changes within three months of them occurring and of sampling from the whole population. As noted by Stinebricker (2001a) graduate cohort or teacher specific data examining the duration of first spells may overstate the extent of teacher attrition as those who subsequently return to the profession are not captured in the sample. The relative weaknesses of our sample, compared to Chevalier et al. (2001), include the shorter observation period (15 months) and the lack of detailed information on educational history (e.g. A-level scores) and, with respect to recent US studies by Stinebrickner (1998, 2001a), is the lack of workplace information .
} 
shortage of subject-specialist teachers in these areas in UK schools. The majority of teachers (49.6\%) have an Arts, History, Language or Humanities degree or majored in Education (29.7\%) in their highest qualification. As is consistent with a nationally representative survey, our sample of public sector teachers is fairly evenly spread throughout the major geographical regions of England and Wales.

\subsection{Where do former public sector teachers go?}

In our sample there is a high rate of public sector teacher turnover. The percentage of teachers leaving the public sector, on average between 1997 and 2003, is 16.3\% of the annual stock. Given the focus of this paper, we now examine the characteristics of the 907 teachers that we observe leaving the public sector in our data. Of these only 346 (38\%) are observed in work in the next wave (quarter). The vast majority of working former teachers remain in the public sector (222, or $64.5 \%$ of those employed) with a substantial number moving into private sector teaching jobs (92, 26.5\%) and only a few (32, 9\%) ending up in non-teaching private sector employment. Hence we observe over $90 \%$ of former public sector teachers leaving the teaching profession altogether, but $25 \%$ of quitters are retained within public sector employment. ${ }^{10}$

Of those public sector teachers who quit and are next observed in work we now compare some of the job characteristics from the old and new positions of employment. Firstly, we find that only $57 \%$ of quitters had a permanent job whilst in public sector teaching, but $65.6 \%$ report holding a permanent contract in their subsequent employment, which may indicate that job security is important for this group. Secondly, the proportion of those who holding managerial (18.1\%) or supervisory (5.3\%) in their former teaching positions is lower than in their new jobs $(25.7 \%$ and $11.0 \%$, respectively). Hence teachers are moving to jobs with higher levels of recognised responsibility.

Thirdly, the nature of the occupations that former public sector teachers move into is quite revealing. Contrary to general expectations they are not moving to higher status jobs or private sector professional work. Of those we observe in a different occupation the greatest numbers are moving to employment as educational or nursery assistants, physical and fitness training instructors and low grade administrative positions such as clerks, bookkeepers and office assistants. Only a handful are observed moving into private sector training roles or managerial positions. These first destinations of former public sector teachers indicate that teacher retention is apparently much less affected by the lure of private sector professional or managerial occupations than commonly-held perceptions, promoted especially by some Teachers’ unions, would suggest.

\footnotetext{
${ }^{10}$ These figures are quite similar to those found for the US by Scafidi et al. (2002).
} 
Finally, we are able to compare the average number of working hours (self-reported, including overtime, for the week prior to interview) for these 346 quitters in their previous and subsequent jobs. Whilst teaching these individuals averaged 27.5 hours whereas in their new employment they are working on average 29.5 hours. This increase in average hours of work is present for all types of new employment (private sector teaching / non-teaching and other public sector). Clearly, this suggests that hours of work are not higher in public sector teaching and that quitters are willing to put up with a couple of extra hours of work a week in outside employment. However, it is important to note that quitters are more likely to be formerly working in part-time positions within the teaching profession.

\subsection{Relative pay in outside employment and returnees}

Apart from hours (which may partially capture workload), there is also general concern about the level of public sector teachers relative pay. Moreover, despite the evidence discussed earlier that teacher retention may not be very responsive to wage changes, a policy of increasing teaching pay is often advocated by teaching unions. Unfortunately, if we wish to look at wage changes for this group, the data poses the problem that wages are only observed in waves 1 and $5^{11}$. Hence we lack a sufficient sample of reported wages, from the same individual in both public sector teaching and in outside employment (in the next quarter), in order to directly compare actual hourly wage differences in the two jobs.

However, we are able to use all the reported wage information from the entire sample to ascertain the determinants of wages for all public sector teachers (see 5.2 below for more details of how this is done). From the calculation of these predicted wage differences we find that teachers earn on average $22.1 \%$ more per hour than that they would in outside employment. This prediction is entirely consistent with the decline in occupational status observed amongst those teachers who actually quit to work outside public sector teaching, that we noted above. Hence, the information in our sample strongly suggests that both wage rates and hours of work are more favourable in the public sector, compared to outside employment.

Finally, within the time frame of our sample we observe 150 public sector teachers who move out of the profession for at least one wave of the survey (a three month period) and then subsequently return to a similar teaching position. They represent $16.5 \%$ of the sample of quitters. The vast majority (114) are observed back in teaching two waves (six months) after they previously reported being a public sector teacher, with an additional 36 individuals only returning three waves

\footnotetext{
${ }^{11}$ Hence we do not have any wage information for former public sector teachers who leave the panel before wave 5 . In addition, the non-response rate to the wage information questions is around 25\% in the QLFS.
} 
(nine months) later. ${ }^{12}$ Of these returnees $70 \%$ spent the intervening period in non-participation, 20\% were employed in other public sector jobs, $7 \%$ held a private sector teaching job and just 3\% were working in other private sector occupations. Evidently, short-term career breaks, in many cases for child-rearing purposes, dominate in this group of returnees and it is clearly the case that a substantial minority of teachers who quit the profession do so only temporarily.

\section{Econometric Framework}

\subsection{The basic duration model}

Given that our primary interest is in analysing the determinants of teacher quits, we begin by specifying the hazard rate $\theta$ of a public sector teacher $i$ quitting at time $t$ as:

$$
\theta_{i t}=\lambda_{t} e^{x_{i t} \beta}
$$

which means we take the standard Proportional Hazard specification. Here, $\lambda_{t}$ is the baseline hazard (which is allowed to be non-parametric, i.e. it is taken to be piece-wise constant); $x_{i t}$ is a vector of individual characteristics. With this hazard rate, the probability of observing a teacher quitting the public sector between $T_{k-1}$ and $T_{k}$ can then be written as:

$$
P\left\{T_{k-1}<t \leq T_{k} \mid x_{i t}, t>T_{k-1}\right\}=1-\exp \left(-\int_{T_{k-1}}^{T_{k}} \lambda_{t} * \exp \left(x_{i t} \beta\right) d t\right)
$$

which means that the probability of quitting public sector teaching between $T_{k-1}$ and $T_{k}$, given that it is larger than $T_{k-1}$, equals one minus the integrated hazard of that period. The big advantage of this hazard model is that it naturally takes account of right-censoring, which applies to most of our data (the high rate of attrition in the QLFS was noted earlier). Unusually for this model, we allow for several time-varying characteristics, such as the number of children, marriage, and year effects. We estimate this model both for the whole sample and just for those who are secondary school teachers.

An important question is whether we can include unobserved heterogeneity within this model (see Dolton and van der Klaauw 1995a, 1999; Stinebrickner, 1998, 2001a). The problem in this

\footnotetext{
${ }^{12}$ Of course these numbers are not necessarily representative due to the construction of our data, which only interviews individuals for five waves, and because of sample attrition.
} 
respect is that we only have 907 observed transitions from teaching to other states. The standard method of allowing for unobserved heterogeneity is to focus only on those teachers whom we observe entering the profession, and to infer from the interaction between duration and the effect of the explanatory variables on the hazard rate the nature of the unobserved heterogeneity distribution (see Van den Berg 2001, for a review of modelling options in our context). This way, however, is blocked for us, because the number of teachers that we observe both entering and leaving public sector teaching jobs, within the five quarter window of the data, is far too small for meaningful econometric results to be obtained.

Another approach would be to make the assumption that the stock of public sector teachers is stable over time, and to use information on the aggregate flows to infer the distribution of unobserved heterogeneity. Given the large changes in the stock of teachers over the last few decades, we reported earlier, such an avenue is also precluded. Indeed, if the stock had been constant, there would have been little motivation for the analysis used in this paper. We hence focus on a model without unobserved heterogeneity, but note that in general any bias would push our estimated coefficients downward. As a practical advantage, however, having no unobserved heterogeneity reduces the importance of functional form for our estimates, because the identification of unobserved heterogeneity in single-spell data is known to be heavily dependent on functional form (e.g. Baker and Melino, 2000). ${ }^{13}$

\subsection{Predicting relative wages}

Of special interest is the construction of the variable denoting the expected proportional hourly wage difference between public sector teaching and alternative employment for our sample. Whilst previous UK studies have used non-teaching graduate earnings or average non-manual occupational earnings as the relative wage point of comparison for teachers here we are able, to some extent, to impute the actual wages that teachers would receive in alternative employment. As mentioned previously, one practical issue here is that wages are only collected twice in the panel, and, as such, the actual wage difference is not always directly observed. Therefore we compute both the likely wages for teachers in public sector employment, which broadly follows a national grading schedule, and is hence well-predicted, and the wages in outside employment. Using observations from the

\footnotetext{
${ }^{13}$ We may note in this context that assuming the unobserved heterogeneity distribution to be a particular shape (as in Dolton and van der Klaauw, 1995, 1999) is now known to be a very restrictive assumption that heavily influences the parameters. The assumption employed by Stinebrickner (1998, 2001a), that unobserved heterogeneity at the start of the sample is independent of observed characteristics, is 'useful' in the sense that it does not require one to look at observed entrants. Its disadvantage is that it is only reasonable when the time spent in the sample is a meaningful duration (i.e. when the time spent in the sample is a major determinant of quitting behaviour instead of time spent in teaching).
} 
latter group, comprising individuals who are observed both as public sector teachers and in outside employment in our sample, ${ }^{14}$ we then predict the hourly wage difference, between employment as a public sector teacher and employment elsewhere, for each individual.

The usefulness of this prediction obviously depends on the quality of the information used for predicting wages. We use not only all the usual human capital variables (age, educational qualifications, job characteristics etc.), but also, in order to help account for selection, use intentions information (on whether an individual intends to quit because of dissatisfaction with pay). Additionally job status (permanent / temporary) and general ability indicators (number of ' $\mathrm{O}$ ’ and 'A' levels) were used. The identification of the effect of outside wages in the duration model is achieved through including variables with which we predict wages but we do not allow to directly predict durations. The validity of the estimated effect of outside wages on duration thus depends on how reasonable it is that these 'instruments' only affect duration via their effect on outside wages. To give some robustness to the results, we have used several instruments.

One main instrument is information on quitting intentions i.e. whether a teacher is dissatisfied with their pay to the extent that he or she is looking for alternative employment. We would argue that the effect of being dissatisfied with pay on teacher durations is solely due to the wages these teachers could earn outside teaching (i.e. outside wages). Another instrument we use is basic (subdegree) educational qualifications which are not directly rewarded in the teaching profession (given that most of our sample holds a degree or teaching qualification) but that do influence outside wage opportunities. Therefore we assume that the number of ' $O$ ' and ' $A$ ' levels only affects teacher duration via their influence on outside wages. We also take permanency of the job as a reflection of the degree to which individuals have invested more heavily in job-specific human capital and thus have more to lose from quitting public sector teaching, in terms of relative wages. These instruments appear intuitively quite reasonable, but as with any study which does not observe strict exogenous variation in wages, some caution should be exercised in interpreting the results. To aid identification, we were also able to use the small number of individuals for whom we observed wages, both in teaching and in outside employment, as direct observations on wage differences. For these individuals we have no need to rely on exclusion restrictions to identify the outside-wage effect.

It is useful to reflect on why there is little exogenous variation in relative wages given that over the period 1997-2003 there were a number of changes in teacher wages. These were typically recommended by the School Teachers Review Body and implemented by the government as annual pay increases. Unfortunately, their usefulness for helping us to identify the influence of relative

\footnotetext{
${ }^{14}$ This group includes both entrants to the public sector teaching profession and quitters.
} 
wages on teachers quitting behaviour is limited by the fact that most of these potentially exogenous changes affected all teachers uniformly. Of those which did not, either the group is affected is too small to be adequately represented in our data (e.g. the $29 \%$ increases in London-weighting allowances implemented in April 2001), or we are unable to accurately identify the individuals concerned (e.g. those receiving management-related pay enhancements since September 2000). Moreover, whilst teacher wages rose on average by 15\%, in real terms over the sample period, nonmanual earnings growth was of a similar magnitude suggesting little change in relative wages.

\subsection{A competing risk framework}

As a more elaborate model, we next distinguish between the two main observed exit states, namely outside employment and non-participation. Denote the hazard rate of quitting public sector teaching by individual $i$ at time $t$ for exit state $j$ as $\theta_{i t}^{j}$ which is specified analogue to (1). The probability of not quitting between $T_{k-1}$ and $T_{k}$, given a duration at least as high as $T_{k-1}$, then equals

$$
P\left\{T_{k-1}<t \leq T_{k} \mid x_{i t}, t>T_{k-1}\right\}=\exp \left(-\int_{T_{k-1}}^{T_{k}} \sum_{j} \lambda_{t}^{j} * \exp \left(x_{i t} \beta^{j}\right) d t\right)
$$

This model is estimated by maximum likelihood, yielding estimates of each of the baseline functions $\lambda_{t}^{j}$ and the parameters $\beta^{j}$.

\subsection{Policy simulations}

We use the estimates of the single destination duration model above to address the question of how a policy maker may influence the propensity for a teacher to quit the public sector. As the baseline, we use our model to estimate the proportion of public sector teachers that can be expected to quit in any three month interval. This estimate is defined as:

$$
\text { Quit Proportion }=\frac{\sum_{i} \sum_{t} 1-\exp \left(-\int_{T_{i t-1}}^{T_{i t}} \hat{\lambda}_{t} * \exp \left(x_{i t} \hat{\beta}\right) d t\right)}{N}
$$

where $T_{i t 1}$ denotes the duration in the current teaching job at the start of the three month period of individual $i$ in her $t$ 'th observation, and where $\mathrm{N}$ is the total number of three month observations.

We can now perform policy simulations by manipulating $x_{i t}$. More specifically, we estimate the effect of reducing the proportional wage difference between public sector teaching and other 
employment by $10 \%$. This difference can, in practice, be reduced by either increasing the hourly pay (including overtime) of teachers by $10 \%$, or by reducing the hourly pay in other employment by $10 \%$. In this context, it is worth recalling that $24.5 \%$ of the transitions from public sector teaching are to a non-teaching job in the public sector and that quitters, on average, are predicted to earn 22.1\% lower gross hourly wages in outside employment.

\section{Results}

\subsection{Relative wage predictions}

The estimates from the log hourly wage regressions for public sector teaching wages and outside wages are presented in Table 1. The results from these models appear sensible and the adjusted Rsquared measures are 0.22 for within teaching and 0.31 for outside employment. In particular, for both models age takes the expected quadratic profile and hourly wages are higher for males, for whose who are married or cohabiting, those in permanent jobs, for those with managerial or supervisory duties and those with greater numbers of ' $O$ ' and ' $A$ ' levels. Wages are lower for those who are from ethnic minorities and for those unsatisfied with their pay. The finding that ethnic minority teachers obtain lower wages in the public sector is reflective of labour market discrimination found in other public sector professions (e.g. for nurses see Pudney and Shields, 2000), but the wage gap is much greater in the general labour market (Blackaby et al., 1998; Frijters et al., 2003b). Interestingly, teachers who were born outside the UK report higher earnings both within the public sector profession and in other employment.

Given the recent government concern about the scarcity of subject specialist teachers in the Science area it is noteworthy that such graduates are predicted to be the highest paid in outside employment, in our sample, closely followed by Social Science and Business graduates. However, those who have specialised in Education receive the lowest rewards of all those individuals with degree level qualifications. Reassuringly, wages reported by proxy respondents are insignificantly different from those given in person.

We use these estimates to establish the hourly wage differential between public sector employment and the outside job opportunities available to teachers who quit. One very important result is that, on average, hourly wages are found to be $22.1 \%$ higher in the public sector, compared to outside employment. However, this gap varies considerably by age with the greatest relative pay differential (loss) occurring for those aged 38 (see Figure 1), and a much lower differential amongst recent graduates and, particularly, older teachers. The hourly wage differential is also quite stable over time, with a gap of $21.7 \%$ at the start of our sample period and the difference at the end being $22.8 \%$. 


\subsection{Duration results: single destination hazard models of teachers’ quitting decisions}

The full results from the single risk proportional hazard models are presented in Table 2. As a check on the ability of the single destination model to fit the data, we first predict the proportion of the current teaching stock to leave in a 12-month period using our estimates. The prediction proportion is $16.30 \%$, which corresponds very closely to the raw data estimate of $16.28 \%$ which indicates that the single risks model fits the aggregate raw data very well. We begin our discussion of the detail estimates with the results based on the whole sample of teachers.

The individual determinants of quitting teaching in the public sector appear to be quite intuitive. Older teachers, those who are female, those with a dependent child under 3 years old and individuals with a limiting long-term health condition are most likely to leave the public sector profession. Interestingly, given the recent reliance on recruitment form overseas, those teachers who were born abroad are significantly less likely to leave employment in the public sector, whilst ethnicity makes no statistical difference to the probability of quitting. Full-time employees and those with managerial or supervisory duties have significantly lower probabilities of quitting, compared to part-timers and those without additional job responsibilities. Importantly, conditional on controlling for relative wage differentials, teachers with degree level qualifications in Science subjects are the least likely to exit from public sector teaching (this contrasts with the finding of Chevalier et al., 2002, using graduate cohort data). All teachers living outside of Greater London are less likely to quit than those within that region (see also Chevalier et al., 2002), but only significantly so for those residing in the Southern half of England. Relative to secondary school teachers, those working in primary schools, with special needs children, as school inspectors or in other teaching jobs are significantly less likely to quit employment as a public sector teacher. These findings have important implications for the targeting of policies aimed at improving teacher retention.

In the right hand columns of Table 2 we report the results from estimating the same single risks proportional hazard model on the sample of just secondary school teachers. Amongst this group who generally have the highest probability of quitting we find that gender, marital status, having a young dependent child and having a limiting long-term health condition are less statistically significant in determining the probability of quitting, suggesting that they are more important determinants amongst primary school and other teachers. In contrast age, the number of children and full-time status all have a greater impact on the likelihood of quitting amongst secondary school teachers. The probability of quitting across different degree specialists in the secondary school sector follows a similar pattern to that observed amongst all teachers with Science, Social Science / 
Business and Arts / History / Language / Other graduates all approximately twice as likely to quit than graduates who specialise in education at degree level.

We now turn to a discussion of the effect of relative wages on leaving public sector teaching. Given our instruments, we find that our predicted log wage differential variable is positive and significant at the $1 \%$ level in both the sample of all teachers and that containing only secondary school teachers. Individuals with a $1 \%$ higher wage outside of teaching were $0.57 \%$ more likely to quit public sector teaching. Secondary school teachers are found to be slightly more responsive to outside wages with a $0.67 \%$ increase in quitting probability from the same wage change. However, it is clear that both wage responses are quite inelastic implying that large wage differentials would be necessary to have an substantial impact on the probability of individuals quitting the public sector. We return to this issue, and examine it in more detail, in Section 6.4.

\subsection{Competing risks}

Whilst the single destination hazard model is informative about the characteristics of teachers who leave the public sector, and the overall importance of wages in this decision, it provides less information about the factors influencing the choice of alternative destinations for teachers. Due to lack of data, we model only the two main competing destinations for public sector teachers: namely, other employment (dominated by other public occupations, as we saw earlier) and nonparticipation. Of the 7989 teachers retained for the duration analyses, 346 went into other employment and 561 went into non-participation. The results, on a necessarily more limited set of covariates, are provided in Table 3.

These estimates are also fairly intuitive. The likelihood of leaving public sector teaching into non-participation increases with age, being female, being part-time and having a limiting long term health condition. The difference is especially pronounced for those with a dependent child under three years old whose probability of moving to non-participation is $78 \%$ higher. This evidence strongly confirms that child-rearing choices are behind many quitting decisions. Interestingly, teachers born abroad are significantly less likely to quit to non-participation, controlling for the effects of age and gender, amongst other things. Individuals in rented accommodation are 37\% more likely to depart into other employment than home owners whilst teachers with supervisory responsibilities are nearly $70 \%$ more likely to exit into other jobs than those without. However, this effect is not repeated amongst those with managerial duties. As was apparent from Table 2 primary school and other teaching professionals are significantly less likely to leave the public sector profession than secondary school teachers and these results show that this finding holds for both alternative destinations. 
As in the single risks case, we again find that teachers with degree level qualifications are the less likely to quit than those without and that Science graduates have the lowest quitting probability of all public sector teachers. However, it is interesting to note that there is no significant coefficient associated with Social Science / Business degrees suggesting that they are the most likely group of graduates to exit to other employment. It is also striking that there is no significant residential location effect on the probability of quitting to work outside public sector teaching, but that teachers living in Greater London are the most likely to enter non-participation. This latter finding may partially reflect relatively high child-care costs in this region which, if this is the case, may be an area which can be addressed by policymakers (see Stinebrickner, 2002).

One interesting result is the impact of the wage differentials on exits from public sector teaching. We find that the higher is the predicted wage offer the greater the likelihood that teachers move into non-participation. However, relative wage differentials do not significantly influence the decision to move into outside employment. It thus appears that those most capable of earning high outside wages move to non-participation, rather than realise those wage opportunities outside public sector teaching. In a similar analysis we found the same effect for nurses (Frijters et al. 2003a). This is further evidence to suggest that teachers are not departing the public sector for reasons due to pay.

\subsection{Policy Simulations}

In the sample we are able to calculate the average annual flows into and out of teaching, over our sample period of 1997 to 2003. Inflows into public sector teaching are equivalent to $17.05 \%$ of the stock a year, whereas the outflows are $16.3 \%$. If the percentage of teachers leaving and entering the public sector remain constant, then it is straightforward to see that the stock of public sector teachers will increase by about $0.75 \%$ per year without any policy intervention. Using the predicted proportion of outflows as the benchmark, we simulated the effect of a $10 \%$ higher wage for public sector teachers and found that it would reduce the percentage of teachers leaving in any 12-month period by just $0.74 \% .{ }^{15}$ Importantly, this may underestimate the effect of the relative wage hike on the stock of public sector teachers as there may be a further beneficial effect on recruitment. However, an untargeted approach would be a very costly intervention as an across the board 10\% wage increase for teachers would cost well in excess of 1.5 billion pounds in order to retain just an extra 3,012 teachers in the profession - nearly 500,000 thousand pounds per teacher. Training and recruiting new teachers is clearly more cost effective - at a cost of less than 15,000 pounds each.

\footnotetext{
${ }^{15}$ This estimate has the same statistical significance as that of the log wage differential parameter in the duration model.
} 
Since the governments' own figures anticipate a 7\% reduction in the number of primary school pupils, and a 6\% fall in the number of secondary school pupils, over the next decade (DFES, 2004) even a fall in the number of teachers (by approximately 5,000) from present levels would enable it to hit PTR targets in 2012. However the distribution of required changes between primary and secondary school teachers is not even. An small increase in secondary school teachers from present levels (of around 500) is needed and, as we saw from our model estimates above, these are the teachers who are most likely to leave the public sector profession. Indeed the average annual flows into and out of secondary school teaching are 16.8\% and 19.1\%, respectively, during 1997 to 2003. Hence, other things being equal, this suggests an annual decline of $2.3 \%$ in the stock of public sector secondary school. This group of teachers were also the most responsive to relative wage differentials. However, a $10 \%$ increase in the relative wage of secondary school public sector teachers would only reduce the percentage of this group of teachers leaving in any 12-month period by around $0.77 \%$. Higher pay is clearly not going to solve the supply shortfall in this area.

\section{Conclusions}

The question of how to tackle persistent teacher shortages is an important issue currently facing policy-makers in many countries across the world. In the UK there has been relatively little economic research into the teaching labour market, despite it being one of the largest occupational groups. In this paper we contribute to the literature by undertaking a detailed empirical investigation into the quitting behaviour of public sector teachers in England and Wales, using nationally representative panel data drawn from the Quarterly Labour Force Survey. We estimated both single and competing risk duration models and explored the impact of relative wages on teacher retention.

Our results are interesting and somewhat contrary to widely-held perceptions. We predict that current hourly wages of public sector teachers are about $22 \%$ higher than the wages they would receive in outside employment. Moreover, teachers who quit work an average of 2 hours more per week than they did in the public sector and are mainly engaged in non-professional occupations. Whilst teachers quitting decisions are significantly influenced by relative hourly wage rates, we find that the magnitude of this effect on teacher retention is small. Our policy simulations of the impact of a $10 \%$ wage increase for all public sector teachers, costing in excess of 1.5 billion pounds, indicates only a $0.74 \%$ reduction in departures - equivalent to just 3,012 extra teachers retained in the public sector each year. Hence our analysis suggests that there is little scope for improving teacher retention through increasing wages in the public sector profession in England and Wales. However, whilst the finding that wages have little impact on labour supply is more generally 
supported by the wider labour supply literature (see Borjas, 2000), some caution should be given to our results considering that we were not able to utilise purely exogenous changes in teachers wages to identity the wage effect. Nevertheless, we have argued that the identifying restrictions we have used are reasonable in this context.

We also show that the majority of quitters leave the labour force altogether, a decision which is strongly influenced by the presence of dependent child under the age of three years old. Additionally public sector teachers living in Outer London are the most likely to move into nonparticipation. These findings suggest that child-care provision may be more relevant to the quitting decision for a large proportion of public sector teachers (see also Stinebrickner, 2002).

Policies focussed on increasing the number of new graduates entering public sector teaching, rehiring of former teachers currently not in work or engaged in other employment and recruitment from overseas may also be cost-effective ways of enhancing the supply of teachers. However, there is a clear compositional problem with secondary school teachers being most likely to quit the profession but increasing numbers being required in order to meet government pupil-teacher ratio targets over the next decade. This highlights the need to identify and address those non-pecuniary aspects of employment as a public sector teacher which are driving such individuals into accepting less well paid and lower status jobs outside the profession.

\section{References}

Baker, M. and Melino, A. (2000). Duration dependence and nonparametric heterogeneity: a Monte Carlo Study. Journal of Econometrics, 96, pp. 57-393.

Ballou, D. and Podgursky, M. (1995). Recruiting smarter teachers. Journal of Human Resources, 30, 2, pp. 326-338.

Blackaby, D., Leslie, D., Murphy, P., O’Leary, N. (1998). The ethnic wage gap and employment differentials in the 1990s: evidence for Britain. Economics Letters, 58, pp. 97-103.

Blundell, R. and MaCurdy, T. (1999). Labor supply: A review of alternative approaches. In Ashenfelter, O. and Card, D. (eds.) Handbook of Labor Economics, Volume 3a. Elsevier: Amsterdam.

Borjas, G. (2000). Labour Economics (2 ${ }^{\text {nd }}$ Edition). McGraw-Hill: Boston.

Brewer, D.J. (1996). Career paths and quit decisions: evidence from teaching. Journal of Labor Economics, 14, 2, pp. 313-339.

Chevalier, A., Dolton, P. and McIntosh, S. (2002). Recruiting and retaining teachers in the UK: an analysis of graduate occupational choice from the 1960s to the 1990s. Centre for Economics of Education, Discussion Paper no. 21, London. 
Chung, T-P., Dolton, P. and Tremayne, A. (2004). The determinants of teacher supply: time series evidence for the UK, 1962-2001. Paper presented at Royal Economic Society Annual Conference, April 2004, Swansea.

DFES (2004). Statistics of education: school workforce in England. 2003 edition. The Stationary Office: London.

Dolton, P. (1990). The economics of UK teacher supply: the graduate's decision. Economic Journal, 100, 400, pp. 91-104.

Dolton, P. (2004). Teacher supply. Forthcoming in The Handbook of Education Economics, edited by E. Hanushek and F. Welch, North Holland: Amsterdam.

Dolton, P. and van der Klaauw, W. (1995a). Leaving teaching in the UK: a duration analysis. Economic Journal, 105, 429, pp. 431-444.

Dolton, P. and van der Klaauw, W. (1995b). Teaching salaries and teacher retention. In Assessing Educational Practices: the contribution of economics, edited by Becker, W.E and Baumol, W.J, MIT Press: Cambridge, Mass., pp. 239-272.

Dolton, P. and van der Klaauw, W. (1999). The turnover of teachers: a competing risks explanation. Review of Economics and Statistics, 81, 3, pp. 543-552.

EURYDICE (2002). The teaching profession in Europe: Profile trends and concerns. Report II. Teacher supply and demand at general lower secondary level. Eurydice European Unit: Brussels.

Falch, T. and Strom, B. (2004). Teacher turnover and non-pecuniary factors, Working Paper No. 1/2004, Department of Economics, Norwegian University of Science and Technology: Trondheim.

Flyer, F. and Rosen, S. (1997). The new economics of teachers and education. Journal of Labor Economics, 15, 1, pp. S104-S139.

Frijters, P., Shields, M. and Wheatley Price, S. (2003a). Investigating the quitting decisions of nurses: panel data evidence from the British National Health service. IZA Discussion Paper, no. 794, IZA: Bonn.

Frijters, P., Shields, M., Theodoropoulos, N. and Wheatley Price, S. (2003b). Testing for employee discrimination using matched employer-employee data: theory and evidence. IZA Discussion Paper, no. 807, IZA: Bonn.

Hanushek, E.A., Kain, J.F. and Rivkin, S.J. (2004). Why public schools lose teachers? Journal of Human Resources, forthcoming.

Loeb, S. and Page, M.E. (2000). Examining the link between teacher wages and student outcomes: The importance of alternative labour market opportunities and non-pecuniary variation. Review of Economics and Statistics, 82, 3, pp. 393-408.

Manski, C. (1987). Academic ability, earnings and the decision to become a teacher: Evidence from the National Longitudinal Study of the High School class of 1972. In Public Sector Payrolls edited by D. Wise, University of Chicago Press: Chicago, IL.

Murnane, R.J. (1994). Selection and survival in the teacher labor market. Review of Economics and Statistics, 66, pp. 513-518. 
Murnane, R.J. and Olsen, R.J. (1989). The effects of salaries and opportunity costs on duration in teaching: evidence from Michagan. Review of Economics and Statistics, 71, pp. 347-352.

Murnane, R.J. and Olsen, R.J. (1990). The effects of salaries and opportunity costs on length of stay in teaching: evidence from North Carolina. Journal of Human Resources, 25, 1, pp. 106-124.

NUT (2003). NUT submissions to the school teacher review body 2003. National Union of Teachers: London.

Pudney, S. and Shields, M. (2000). Gender, race, pay and promotion in the British nursing profession: estimation of a generalised ordered probit model. Journal of Applied Econometrics, 15, pp. 367-399.

Scafidi, B., Sjoquist, D. and Stinebrickner, T.R. (2002). Where do teachers go? Mimeo.

Shields, M. A. (2004). Addressing nurse shortage: what can policy-makers learn from the econometric evidence on nurse labour supply? Economic Journal, forthcoming.

Siniscalco, M.T. (2002). A statistical profile of the teaching profession. ILO: Geneva and UNESCO: Paris.

Smithers, A. and Robinson, P. (2002). Factors affecting teachers' decision to leave the profession. Research Report No. 430, Department for Education and Skills: London / University of Liverpool.

Stinebrickner, T.R. (1998). Am empirical investigation of teacher attrition. Economics of Education Review, 17, 2, pp. 127-136.

Stinebrickner, T.R. (2001a). A dynamic model of teacher labor supply. Journal of Labor Economics, 19, 1, pp. 196-230.

Stinebrickner, T.R. (2001b). Compensation policies and teachers decisions. International Economic Review, 42, 3, pp. 751-779.

Stinebrickner, T.R. (2002). An analysis of occupational changes and departure from the labour force. Journal of Human Resources, 37, 1, pp. 192-216.

Sturman, L. (2002). Contented and committed? A survey of quality of working life amongst teachers. National Foundation for Educational Research: Slough, UK

Theobald, N.D. (1990). An examination of the influence of personal, professional, and school district characteristics on public school teacher retention. Economics of Education Review, 9, 3, pp. 241-250.

Theobald, N.D. and Gritz, R.M. (1996). The effects of school district spending priorities on the exit paths of beginning teachers leaving the district. Economics of Education Review, 15, 1, pp. 11-22.

Van den Berg. G.J. (2001). Duration models: specification, identification, and multiple durations. In J.J. Heckman and E.E. Leamer (eds.), Handbook of Econometrics, Volume 5, North-Holland, Amsterdam.

Zabalsa, A. , Turnbull, P. and Williams, G. (1979). The Economics of Teacher Supply. Cambridge University Press: Cambridge. 
FIGURE 1: Proportional Hourly Wage Loss From Leaving Public Sector Teaching By Age

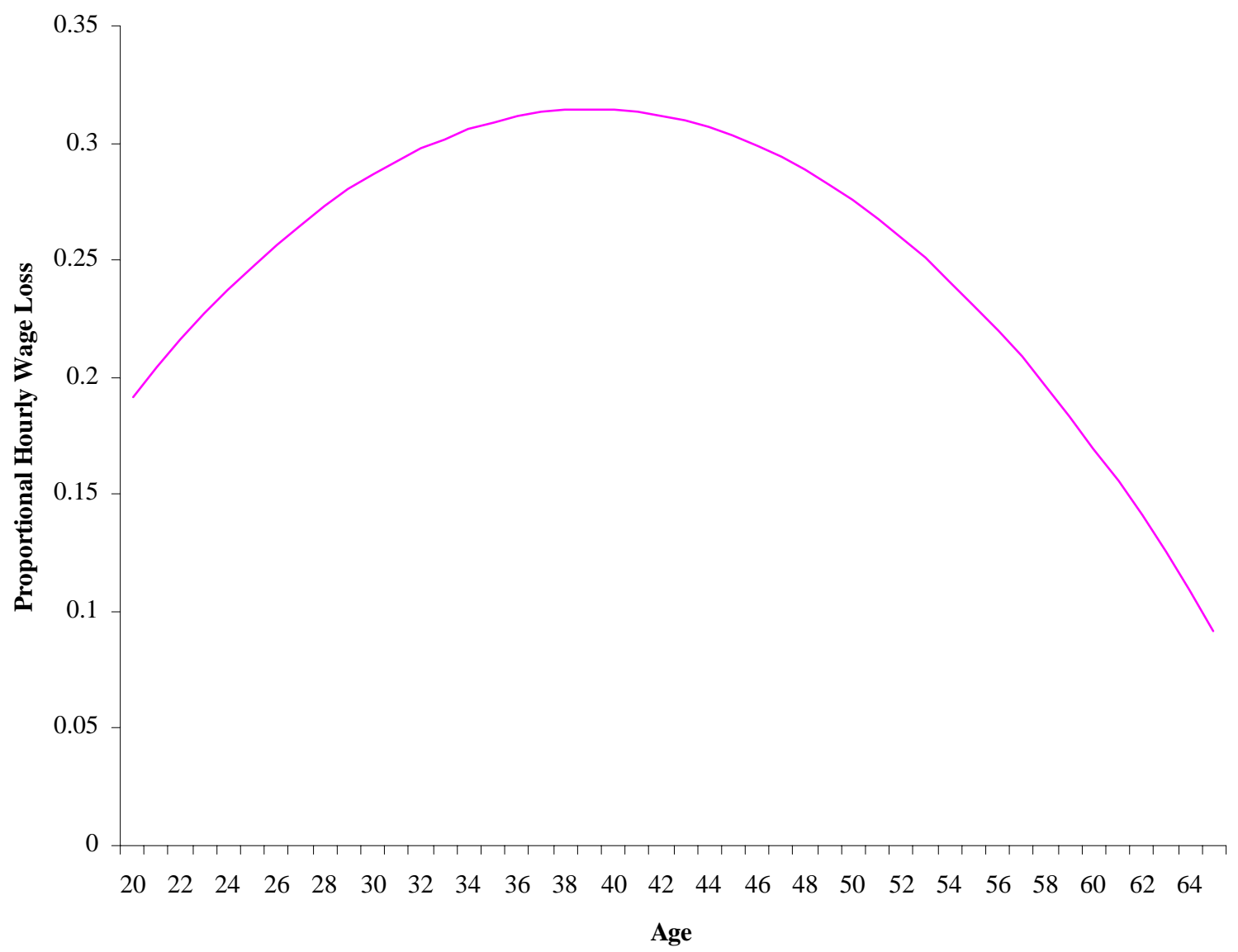


TABLE 1: OLS Models of Public Sector Teacher and Outside Employment Wages

\begin{tabular}{|c|c|c|c|c|}
\hline \multirow[t]{2}{*}{ Explanatory Variables } & \multicolumn{2}{|c|}{ Public Sector Teacher Wages } & \multicolumn{2}{|c|}{ Outside Employment Wages } \\
\hline & $\beta$ & $t$-stat & $\beta$ & $t$-stat \\
\hline$\overline{\text { Age }}$ & 0.097 & 63.31 & 0.071 & 15.30 \\
\hline Age-squared /100 & -0.103 & -51.55 & -0.069 & -11.80 \\
\hline Male & 0.053 & 7.03 & 0.032 & 1.33 \\
\hline Married or cohabiting & 0.031 & 3.70 & 0.070 & 2.61 \\
\hline Number of children & 0.004 & 0.34 & -0.015 & -0.38 \\
\hline Immigrant & 0.026 & 1.75 & 0.128 & 3.09 \\
\hline Ethnic minority & -0.038 & -1.75 & -0.190 & -3.25 \\
\hline Proxy respondent & -0.004 & -0.50 & -0.004 & -0.15 \\
\hline Full-time & -0.017 & -1.73 & 0.140 & 5.33 \\
\hline Permanent job & 0.047 & 4.30 & -0.023 & -0.78 \\
\hline Limiting long-term health condition & -0.024 & -6.46 & -0.017 & -1.33 \\
\hline Training in last 13 weeks & 0.009 & 1.36 & 0.015 & 0.70 \\
\hline Unsatisfied with pay in teaching & -0.117 & -2.82 & -0.060 & -0.72 \\
\hline Has managerial duties & 0.115 & 15.44 & 0.111 & 4.29 \\
\hline Has supervisory duties & 0.070 & 5.23 & 0.002 & 0.38 \\
\hline Degree / PG Certificate in Education & 0.013 & 1.90 & 0.077 & 2.79 \\
\hline Degree in Science & 0.020 & 1.86 & 0.210 & 5.97 \\
\hline Degree in Social Science / Business & 0.045 & 3.00 & 0.169 & 3.84 \\
\hline Degree in Arts / History / Language / Other & 0.044 & 5.64 & 0.146 & 5.31 \\
\hline 1 or more 'A' levels & 0.048 & 5.74 & 0.040 & 1.40 \\
\hline 5 or more 'O' levels & 0.124 & 9.81 & 0.109 & 3.50 \\
\hline$\overline{\mathrm{N}}$ & \multicolumn{2}{|c|}{9080} & \multicolumn{2}{|c|}{1358} \\
\hline Adjusted $R^{2}$ & \multicolumn{2}{|c|}{0.222} & \multicolumn{2}{|c|}{0.312} \\
\hline
\end{tabular}

Notes: - The omitted categories are female, single, UK-born, white, not a proxy respondent, part-time, non-permanent job, no limiting long-term health condition, no training in the last 13 weeks, satisfied with pay in teaching, no managerial or supervisory duties, less than degree level highest qualification, less than 5 ' $O$ ' levels and no 'A' levels. The models also include controls for sample years, seasons and regions. 
TABLE 2: Single Risks Proportional Hazard Models for the Quitting Decision of Teachers

\begin{tabular}{|c|c|c|c|c|}
\hline \multirow[t]{2}{*}{ Explanatory Variables } & \multicolumn{2}{|c|}{ All Teachers } & \multicolumn{2}{|c|}{ Secondary School Teachers } \\
\hline & $\beta$ & $t$-stat & $\beta$ & $t$-stat \\
\hline Log wage differential & 0.573 & 3.53 & 0.674 & 3.20 \\
\hline Age & 0.010 & 2.41 & 0.017 & 2.78 \\
\hline Male & -0.401 & -5.16 & -0.127 & -1.21 \\
\hline Married or cohabiting & -0.122 & -1.34 & 0.010 & 0.07 \\
\hline Number of children & -0.078 & -1.88 & -0.132 & -2.24 \\
\hline Dependent child under 3 years & 0.301 & 1.84 & 0.203 & 0.81 \\
\hline Immigrant & -0.405 & -2.83 & -0.610 & -2.57 \\
\hline Ethnic minority & -0.013 & -0.06 & -0.113 & -0.30 \\
\hline Full-time & -1.124 & -14.56 & -1.150 & -9.98 \\
\hline Limiting long-term health condition & 0.217 & 2.19 & 0.184 & 1.18 \\
\hline Training in last 13 weeks & -0.056 & -0.78 & -0.058 & -0.52 \\
\hline Renting accommodation & 0.158 & 1.36 & -0.217 & -1.05 \\
\hline Has managerial duties & -1.346 & -11.20 & -0.749 & -5.21 \\
\hline Has supervisory duties & -0.322 & -1.97 & -0.251 & -0.97 \\
\hline Primary school teacher & -3.537 & -19.22 & - & - \\
\hline School inspector / Special / Other teacher & -2.688 & -15.76 & - & - \\
\hline Degree / PG Certificate in Education & -0.714 & -7.98 & -0.345 & -3.05 \\
\hline Degree in Science & -1.165 & -9.54 & -0.954 & -5.78 \\
\hline Degree in Social Science / Business & -0.681 & -4.43 & -0.743 & -3.06 \\
\hline Degree in Arts / History / Language / Other & -0.829 & -10.36 & -0.624 & -5.46 \\
\hline Living in Inner London & -0.099 & -0.49 & -0.378 & -1.04 \\
\hline Living in South East & -0.242 & -1.75 & -0.378 & -1.92 \\
\hline Living in the South / South West & -0.319 & -2.15 & -0.406 & -1.94 \\
\hline Living in the Midlands & -0.445 & -3.05 & -0.581 & -2.87 \\
\hline Living in the North East & -0.189 & -1.30 & -0.344 & -1.67 \\
\hline Living in the North West & -0.217 & -1.39 & -0.439 & -1.97 \\
\hline Living in Wales & -0.182 & -0.49 & -0.271 & -1.03 \\
\hline Mean Log Likelihood & & & & \\
\hline Number of individuals & & & & \\
\hline Number of three month periods & & & & \\
\hline
\end{tabular}

Notes: - means that the covariate is not included in the model. The omitted categories are female, single, no dependent child under 3 years, UK-born, white, not a proxy respondent, part-time, no limiting long-term health condition, no training in last 13 weeks, owner-occupier, no managerial or supervisory duties, secondary school teacher, less than degree level highest qualification and living in Outer London. The models also include controls for proxy respondent. 
TABLE 3: Competing Risks Proportional Hazard Model for the Quitting Decision of Teachers

\begin{tabular}{|c|c|c|c|c|}
\hline \multirow[t]{2}{*}{ Explanatory Variables } & \multicolumn{2}{|c|}{ Other Employment } & \multicolumn{2}{|c|}{ Non-Participation } \\
\hline & $\beta$ & $t$-stat & $\beta$ & t-stat \\
\hline Log wage differential & 0.171 & 0.26 & 0.820 & 3.94 \\
\hline Age & -0.007 & -0.97 & 0.019 & 3.60 \\
\hline Male & -0.662 & -4.81 & -0.255 & -2.62 \\
\hline Married or cohabiting & -0.117 & -0.77 & -0.157 & -1.31 \\
\hline Number of children & 0.001 & 0.02 & -0.127 & -2.25 \\
\hline Dependent child under 3 years & -0.467 & -1.43 & 0.784 & 3.95 \\
\hline Immigrant & 0.014 & 0.06 & -0.797 & -3.76 \\
\hline Ethnic minority & 0.260 & 0.83 & -0.254 & -0.74 \\
\hline Full-time & -1.013 & -6.34 & -1.196 & -12.14 \\
\hline Limiting long-term health condition & 0.207 & 1.19 & 0.214 & 1.65 \\
\hline Training in last 13 weeks & 0.055 & 0.48 & -0.088 & -0.90 \\
\hline Renting accommodation & 0.371 & 1.96 & 0.007 & 0.04 \\
\hline Has managerial duties & -0.180 & -1.20 & -7.823 & -0.02 \\
\hline Has supervisory duties & 0.696 & 3.40 & -5.484 & -0.12 \\
\hline Primary school teacher & -2.65 & -12.83 & -5.812 & -8.09 \\
\hline School inspector / Special / Other teacher & -1.57 & -8.34 & -6.363 & -6.18 \\
\hline Degree / PG Certificate in Education & -0.699 & -4.67 & -0.756 & -6.40 \\
\hline Degree in Science & -0.738 & -3.28 & -1.493 & -9.03 \\
\hline Degree in Social Science / Business & -0.192 & 0.86 & -1.157 & -4.73 \\
\hline Degree in Arts / History / Language / Other & -0.667 & -4.52 & -0.966 & -9.18 \\
\hline Living in Inner London & -0.243 & -0.79 & -0.570 & -1.89 \\
\hline Living in South East & 0.082 & 0.36 & -0.643 & -3.42 \\
\hline Living in the South / South West & -0.045 & -0.18 & -0.692 & -3.49 \\
\hline Living in the Midlands & -0.293 & -1.18 & -0.734 & -3.77 \\
\hline Living in the North East & 0.022 & 0.09 & -0.512 & -2.64 \\
\hline Living in the North West & 0.091 & 0.34 & -0.576 & -2.77 \\
\hline Living in Wales & -0.332 & -0.93 & -0.458 & -1.39 \\
\hline Mean Log Likelihood & & & & \\
\hline Number of individuals & & & & \\
\hline Number of three-month periods & & & & \\
\hline
\end{tabular}

Notes: The omitted categories are female, single, no dependent child under 3 years, UK-born, white, not a proxy respondent, part-time, no limiting long-term health condition, no training in last 13 weeks, owner-occupier, no managerial or supervisory duties, secondary school teacher, less than degree level highest qualification and living in Inner London. The models also include controls for proxy respondent. 


\section{University Library}

\section{- M M I N E R VA A gateway to Melbourne's research publications}

Minerva Access is the Institutional Repository of The University of Melbourne

Author/s:

FRIJTERS, PF;SHIELDS, M;WHEATLEY PRICE, S

Title:

To teach or not to teach? Panel data evidence on the quitting decision

Date:

2004

Citation:

FRIJTERS, P. F., SHIELDS, M. \& WHEATLEY PRICE, S. (2004). To teach or not to teach?

Panel data evidence on the quitting decision. Department of Economics, The University of Melbourne.

Persistent Link:

http://hdl.handle.net/11343/34304 